\title{
COMBINING LEAN METHODS TO IMPROVE CONSTRUCTION LABOUR EFFICIENCY IN RENOVATION PROJECTS
}

\author{
Hasse H. Neve ${ }^{1}$, Jon Lerche ${ }^{2}$, and Søren Wandahl ${ }^{3}$
}

\begin{abstract}
The construction industry has experienced stagnation and perhaps even a decline in construction labor productivity for decades. This is problematic as labour costs in construction constitute up to $60 \%$ of the total project costs.

This research aimed to investigate further how much complimentary lean construction tools could impact Construction Labor Efficiency (CLE). CLE is a key element in the denominator when calculating Construction Labor Productivity (CLP) because CLP focuses on maximizing value-adding-work time (numerator) and minimizing nonvalueadding-work time (denominator).

A case study research approach with four renovation projects was used to collect Lean Implementation Degree (LID) and CLE data. The research findings showed a strong positive correlation between LID and CLE in the four renovation projects.

The findings have implications for both academia and industry professionals. Academia now has initial results on which future research can be built. Industry professionals now have a better understanding of how lean improves efficiency and hereby better arguments for why lean construction methods must be implemented in future renovation projects.

The research was limited by a small sample size of only four renovation projects. Thus, further research is needed to validate the effects in renovation projects and other types of construction projects as well.
\end{abstract}

\section{KEYWORDS}

Performance, productivity, work sampling, efficiency, implementation, lean.

\section{INTRODUCTION}

Construction Labor Productivity (CLP) is calculated by dividing craftsmen's output (monetary value of the constructed) with craftsmen's input (number of working hours). CLP has a significant impact on construction projects because construction labour costs constitute $40-60 \%$ of the total project costs (Buchan et al. 2006; Kazaz et al. 2008; Smith 2013). Thus, having a high CLP is crucial for the construction project's cost, among others. Despite CLP's importance for construction projects, research has shown that CLP has

Consultant, Senior Associate, PhD, PwC, Aarhus, Denmark, +45 $2879 \quad 1838$, hasse.hojgaard.neve@pwc.com, orcid.org/0000-0003-2311-3529

2 PostDoc, PhD, Department of Business Development and Technology, Aarhus University, Denmark, +45 6013 3595, jon.lerche@ btech.au.dk, orcid.org/0000-0001-7076-9630

3 Professor, Dept. of Civil and Architectural Engineering, Aarhus University, Denmark, +45 4189 3216 , swa@cae.au.dk, orcid.org/0000-0001-8708-6035 
continually declined for four decades (1972-2010) in North America (Neve et al. 2020a), with similar trends in most EU countries (Farmer 2016). One approach to change the problematic development in CLP is improving Construction Labour Efficiency (CLE), which is known to be a key factor in increasing CLP (Neve et al. 2020a). CLE refers to the optimal use of labor time (denominator of CLP). That is when labor work is done with a maximum amount of time spent on value-adding work (better known as Direct Work (DW)) and a minimum of time spent on Non-Value Adding Work (NVAW).

Despite the importance of improving CLE, only a little knowledge exists on how to manage and improve DW and NVAW time in construction projects. Thus, this research aims to explore how significant impact lean construction methods have on CLE. The aim is to provide initial findings to academia and industry on the effects lean construction methods have on CLE. Improving CLE will additionally improve CLP and thus mitigate the main challenge of declining productivity.

\section{BACKGROUND: LABOUR EFFICIENCY AND LEAN IN CONSTRUCTION}

Data on CLE and hereby on how construction laborers use their time can be collected with the Work Sampling (WS) method. The WS method has been used since the 1970s in construction (Gong et al. 2011) and quantifies labor time usage by categorizing direct observations of construction labor work.

The WS method has proven itself to be able to create valuable insights on DW and NVAW time in the flow view (Neve et al. 2020b) of the Transformation-Flow-Value theory by Koskela (2000) in which, the production resource is time (Bølviken et al. 2014). The use of lean methods in construction initiates with the seminal work of Koskela (1992), who suggested that the use of lean in construction can have a significant effect on NVAW time. DW are activities like processing of materials, assembling of elements, etc.

One of the first lean construction tools was the Last Planner System ${ }^{\mathrm{TM}}$ (LPS) (Ballard 2000) which has proven its ability to improve planning effectiveness, e.g., Alarcón et al. (2005); AlSehaimi et al. (2009); Ballard (2000); Lerche et al. (2020a). Later, the lean construction tool Location-Based Scheduling (LBS) emerged (Kenley and Seppänen 2010) and proved its ability to compress construction schedules (Evinger et al. 2013; Lerche et al. 2019a; Lerche et al. 2019b; Seppänen et al. 2014). Takt Time Planning (TTP), which is similar to LBS (Seppänen 2014), has also shown its ability to compress schedules (Heinonen and Seppänen 2016; Lerche et al. 2020b). Only a few research have, though, investigated how DW can be increased. Examples are the Activity Analysis (AA) method (CII 2010) which has proven itself to be able to continuously improve the time construction laborers spend on DW (Gouett et al. 2011; Hwang et al. 2018).

As the latter outline, only a little knowledge exists on how DW time can be improved in construction. Thus, this research investigates if the combined use of lean tools can improve DW by reducing NVAW in construction projects. The complementary tools could be LPS and LBS, which work nicely together (Seppänen et al. 2010).

That limited knowledge exists on how the use of combined lean methods in construction affects CLE in construction and, hereby, the presence of NVAW time, is a gap in the current body of knowledge. This research, therefore, sets out to close this gap by providing an initial answer to the question: "What impact does the use of lean construction have on construction labour efficiency?". 


\section{METHOD}

This research is an explorative case study based on Yin's third case study research design which uses multiple cases and a single unit of analysis. The research design was chosen because it enabled this research to explore if the use of lean methods influenced CLE. The unit of analysis studied was the correlation between the use of lean methods and CLE. The 4 cases are in the following firstly presented. Secondly, the work sampling method used to collect CLE data is outlined, and finally, the data analyses are described.

\section{CASES}

The cases were all renovation projects located in Denmark. Renovation projects have specific characteristics and peculiarities, which are not elaborated in this paper (e.g., Neve et al. 2020b; Kemmer 2018). The cases were similar in building structure consisting of multiple similar apartments in 1, 2, or 3 story buildings. The cases were all planned to go through deep renovation, including interior, installations, and building envelope. The cases are presented in table 1.

Table 1: Data collection from the three cases.

\begin{tabular}{|c|c|c|c|c|}
\hline & Case $1^{*}$ & Case $2^{\star \star}$ & Case $3^{\star \star \star}$ & Case $4^{\star \star \star *}$ \\
\hline Contract type & General & Turnkey & General & Turnkey \\
\hline Duration & 5 years & 4 years & 4 years & 3 years \\
\hline Apartments & 291 & 297 & 601 & 470 \\
\hline $\mathrm{m}^{2}$ & 22,800 & 23,700 & 46,500 & 41,000 \\
\hline Stories & Basement to 2 & Basement to 2 & Basement to 3 & Ground to 1 \\
\hline Originally built & The 1950s & The 1960s & The 1950s & The 1970s \\
\hline \multicolumn{5}{|c|}{ *WS data previously used in Neve et al. (2020b); Neve et al. (2020d); Teizer et al. (2020) } \\
\hline \multicolumn{5}{|c|}{$\begin{array}{l}{ }^{* *} \text { WS data previously used in Neve et al. (2020b); Neve and Wandahl (2018); Teizer et al. } \\
\text { (2020) }\end{array}$} \\
\hline \multicolumn{5}{|c|}{ ***WS data previously used in Neve et al. (2020b); Teizer et al. (2020) } \\
\hline \multicolumn{5}{|c|}{${ }^{* * * *}$ WS data not previously published. } \\
\hline
\end{tabular}

\section{WORK SAMPLING}

The work sampling method was used to collect CLE data from the four cases. The WS data was in this research collected using 7 categories to describe the work. The only one of interest for this research is the category of DW, which directly depicts CLE by quantifying the time construction laborers spent on value-adding work. Value-adding work is the work a given trade spent on doing work that directly adds value to the building, e.g., painting, nailing roof formwork, laying down tiles, etc.

This research followed Thompson's (1987) and Thompson's (1992) recommendation to ensure validity in the collected data. Thus, a minimum of 510 observations was collected for each WS data set to obtain $95 \%$ confidence. The same was also used by Gouett et al. (2011); Hwang et al. (2018).

The data was collected by inexperienced research assistants on cases 1,2, and 3 and by highly experienced management consultants on case 4 . The research assistants were at all-time supervised to secure validity in the data.

The data was on cases 1,2 and 3 collected by observing the majority of trades individually, and case 4 was observed as a whole. The result is for both approaches a valid data set representing each of the cases. For each case, WS data was collected during 5-10 
days of observation. The criterion was that data collection take place during 'normal' production conditions. Thus not during startup, during delivery problems, not during weather issues, etc.

\section{LEAN IMPLEMENTATION DEGREE}

A systematic concept was developed to evaluate the overall Lean Implementation Degree (LID) on each case. The concept consists of several main and subcategories based on a literature review of previous studies related to lean implementation and discussions with peers and industry consultants with expertise in lean. Wandahl's (2014) industry survey of lean in the Danish construction industry provided great inspiration for the six main categories presented in table 2's first row. The subcategories of A, B, and C were defined according to discussions with academic peers and industry consultants. The remaining subcategories were primarily based on the following literature and supplemented with input from discussions: D) comes from Kragh-Schmidt and Johansen (2000), E) is from Lindhard and Wandahl (2014), and F) is from Kenley and Seppänen (2010). When evaluating the different subcategories, a scale from 0 to 5 was chosen, with 0 being total absents of, e.g., knowledge or training and 5 being the full implementation of, e.g., JIT or 5S. The authors and industry consultants evaluated the LID for each case because it was assessed that the project team in each case did not have the necessary knowledge to do this. The LID was subjectively evaluated by authors/consultants through observation during WS data collection and by conservations with the whole project team.

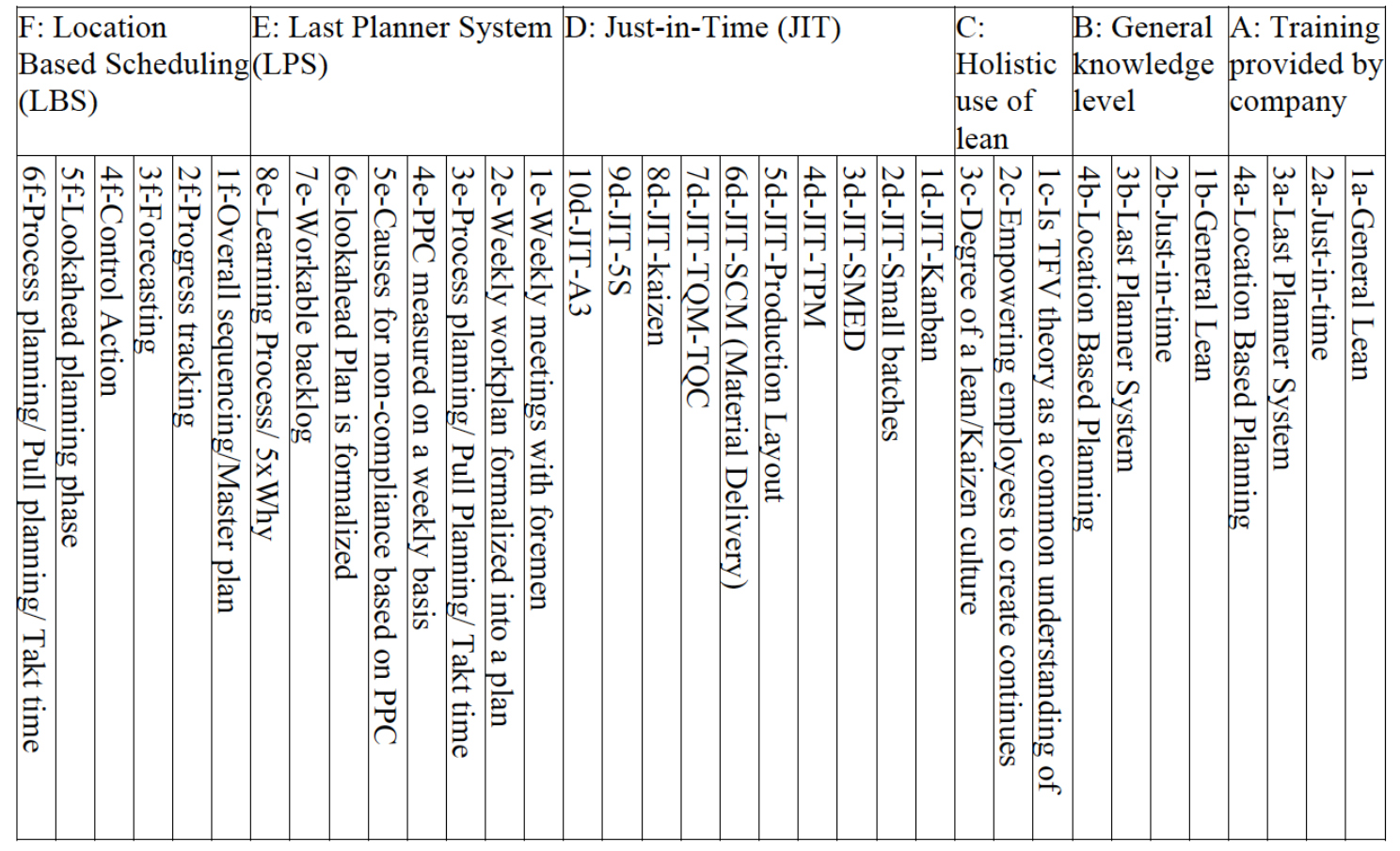

Figure 1: Lean implementation degree evaluation form.

Calculating the LID average was done by weighing averages from the main six categories equally. This was done to avoid making the implementation of, e.g., JIT being more important than, e.g., LBS given its lower number of subcategories. 


\section{ANALYSIS OF DW AND LID DATA}

The analysis of DW and LID data was done using linear regression analyses. The regression model was evaluated through a t-Test determining the model's $95 \%$ coefficient intervals, analysis of regression coefficients to determine the Effect size, R2 to investigate the predictive capabilities, and finally, an ANOVA analysis to determine the statistical confidence level (p-Value). The Effect size (R) was compared to Cohen's (1988) and Cohen's (1992) work categorizing Effect sizes. The p-Value was used as a foundation to determine how statistically valid the identified relationship is. No lower limit for neither the R-value nor $\mathrm{p}$-Value was set since the research was explorative and set out to explore a potential relationship on a small data sample.

\section{RESULTS}

Results from the 4 cases will initially be presented, followed by a statistical analysis testing the relationship between DW and LID. The WS study result is outlined in Table 2. The first row lists the four cases, the second row presents the measured DW levels, and the third row gives the total number of data points from the WS study. The table shows that DW levels are lowest in case 1 and increases steadily going towards case 4 .

Table 2: DW levels from the four studies.

\begin{tabular}{ccccc}
\hline & Case 1 $^{\star}$ & Case 2 $^{\star \star}$ & Case 3 $^{\star \star \star}$ & Case 4 $^{\star \star \star \star}$ \\
\hline DW & $26.0 \%$ & $33.0 \%$ & $36.0 \%$ & $40.7 \%$ \\
N & 29,884 & 3,927 & 13,682 & 861 \\
\hline
\end{tabular}

The LID in the four cases is presented in Table 3. The table's first row starts by showing the main categories of the LID evaluation form ending with the average LID. The following rows outline the results of the LID from the four cases. The LID is evaluated on a scale from 0 to 5 . The table outlines a LID being lowest in case 1, increasing steadily going towards case 4 .

Table 3: Lean Implementation Degree for the four cases. LID is weight average.

\begin{tabular}{ccccc}
\hline & Case 1 & Case 2 & Case 3 & Case 4 \\
\hline A: Training & 0.5 & 0.75 & 1.12. & 1.75 \\
B: Knowledge & 0.5 & 0.75 & 1.5 & 2.25 \\
C: Use & 0 & 0 & 0 & 1 \\
D: JIT & 0.1 & 0.1 & 0.2 & 0.4 \\
E: LPS & 1 & 0.5 & 1.25 & 3.38 \\
F: LBS & 0.00 & 0.67 & 1.17 & 3.17 \\
LID & 0.35 & 0.46 & 0.86 & 1.99 \\
\hline
\end{tabular}

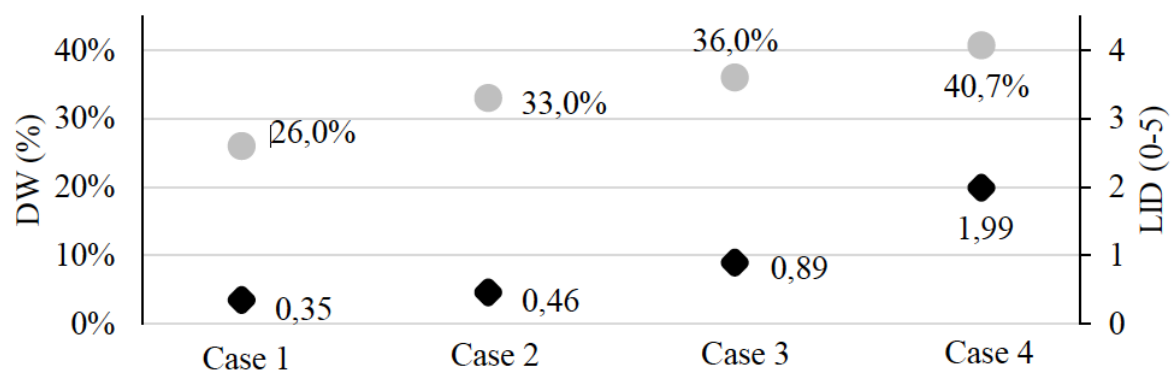

DW: Direct work (\%)

LID: Lean Implementation Degree (0-5)

Figure 2: DW and LID plotted together for the four cases. 
Figure 2 plots the DW levels and LID from the four cases together using two different yaxes, with the left being in \% reflecting the DW level and the right going from 0-5 reflecting the LID score. The plot reveals an apparent linear relationship.

To test the apparent relationship shown in figure 1, linear regression analysis is used. LID acts as the independent (predictor) variable and DW as the dependent (response) variable in the analysis.

Table 4 present the result of the linear regression with the final model, the number of data points $(\mathrm{N}), \mathrm{t}$-Test outlining the $95 \%$ confidence intervals for the predictor coefficient (a) and constant coefficient (b), Effect Size (correlation coefficient (R)) predictive capabilities (R2) and the ANOVA analyses giving the statistical significance level.

Table 4: Result of linear regression analysis.

\begin{tabular}{|c|c|c|c|c|c|c|}
\hline $\begin{array}{c}\text { Model } \\
Y=a x+b\end{array}$ & $\mathrm{~N}$ & a & b & $\mathrm{R}$ & $\mathrm{R}^{2}$ & $\begin{array}{l}\text { ANOVA } \\
p \text {-value }\end{array}$ \\
\hline$y=7.21 x+27.27$ & 4 & $(-4.84 ; 19.26)$ & $(13.68 ; 40,87)$ & .876 & .768 & .124 \\
\hline \multicolumn{7}{|c|}{$y=a x+b$ means that, $x=L I D, b=$ constant and $y=$ predicted DW level } \\
\hline
\end{tabular}

The linear regression analysis is also plotted in Figure 3 with DW and LID data from the four cases to validate the regression model visually. Figure 2 confirms both the linear tendency and the results of the linear regression analysis in Table 4.

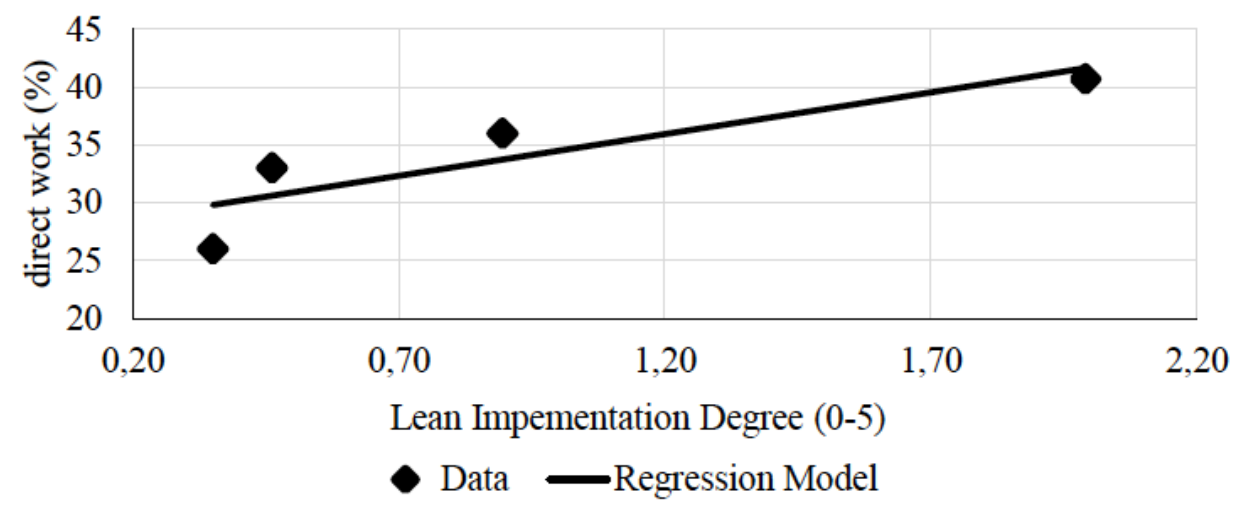

Figure 3: Direct work and lean implementation degree data from the four cases together with the regression model.

With the above result, the RQ: "What impact does the use of lean construction have on construction labour efficiency" can now be answered.

Firstly, the regression analysis reveals an effect size (R) of .876, which far exceeds Cohen's (1988) and (1992) lower limit at, 5 defining a large effect size. The predictive capabilities (R2) match well with the coefficient's confidence intervals looking at Figure 2. This shows that the Lean Implementation Degree has a significant effect on CLE.

Secondly, looking at the statistical significance level at $87.6 \%(\mathrm{p}=.124)$, this means that in 1 out of 8.1 cases, the changes in DW are not explained by LID. This is lower than the $95 \%(\mathrm{p}=.05)$ statistical confidence level, which is typically regarded as the lower limit where the risk of a false result is 1 out of 20. This means that the result is relevant and shows a clear trend, but it includes some uncertainty. The low p level is often seen when few cases constitute the sample size and were from the beginning seen as a limitation in this research. 


\section{DISCUSSION AND LIMITATIONS}

The model's range is defined by the data and shows a span between LID $=.35$ and $\mathrm{LID}=1.99$, predicting DW at respectively $29.8 \%( \pm 17.8 \%)$ and $41.6 \%( \pm 37.6 \%)$, which fits well with the data on $26 \%$ and $40.7 \%$. Looking beyond the model's range using $\mathrm{LID}=0$ and $\mathrm{LID}=5$, the model predicts $\mathrm{DW}$, respectively, at $27.3 \%( \pm 13.6)$ and $63.3 \%$ $( \pm 73.8)$. The predicted DW values at $\mathrm{LID}=0$ are realistic, as the model is based on LID as low as 0.35 . The predicted $\mathrm{DW}$ on $63.3 \%$ at $\mathrm{LID}=5$ contains a considerable uncertainty which is natural knowing that $\mathrm{LID}=5$ is far from the highest data point on $\mathrm{LID}=1.99$ used to make the model. Despite the uncertainty, it is quite interesting to see that previous analysis of the same WS data (Neve et al. 2020b; Neve et al. 2020c) unveiled that the refurbishment systems have the capacity to perform in this range. Neve et al. (2020c) further did a literature review of previous DW values from the literature, also confirming that a DW level at $63.3 \%$ is realistic. However, a $\mathrm{LID}=5$ is likely not needed to manage a 'lean project,' as not all tools in the lean toolbox are required to optimize the project.

Neve et al. (2020c) go further and argues that having specific and ambitious DW targets to reach is an important part of creating motivation to change and, hereby, increase DW levels through lean implementation. Neve et al. (2020c) further explain that a key to increasing DW is bringing down variability in the project production system. That variability negatively influences performance in construction projects is also shown in Tommelein et al. (1999) and Lindhard (2014). Lean construction tools as the last planner system (Ballard 2000) is known to decrease variability. Thus seeing that higher LID degrees correlate with higher DW levels seems natural.

Having change targets and the methods to achieve them is an important step towards change and improvements. Understanding how a project system behaves is another key element in changing it, and both the work of Tommelein et al. (1999) and Lindhard (2014) is a testimony to that. Neve et al. (2020b) investigate system behaviors in renovation projects focusing on how time is used and identifies five specific system behaviors. Specifically, the system behavior, which shows no connection between the type of work and DW level, is highly relevant when setting DW targets to motivate lean implementation. Understanding this system behavior in renovation projects enables one to set overall targets for projects and, hereby, motivate the implementation of, e.g., lean tools listed in the LID evaluation form in figure 1.

As the above shows, the model is limited by a small sample. All data further stems from renovation projects thus might not be applicable to other construction production systems. Further, other management initiatives and evaluation forms have proven their ability to predict project-based production performance (Ballard 2000; Caldas et al. 2015; Nasir et al. 2016) and increase DW levels (CII 2010; Gouett et al. 2011; Hwang et al. 2018). Thus there's a risk that the LID scheme applied needs alterations or additions to cover the management initiatives that can increase DW fully. Therefore, further research is needed to expand knowledge on topics outlined in this section.

Investing in lean implementation or/and research in related areas such as an automated collection of WS data requires companies and national entities to see the potential as, e.g., economic. The work of Neve et al. (2020a) reveals that the economic potential of increasing DW with just $1 \%$ in North America is 5.4 billion dollars annually. Looking towards other work focusing on DW, only a $1 \%$ increase seems very conservative (Gouett et al. 2011; Hwang et al. 2018; Neve et al. 2020c). The continuing challenge of using the WS method is the current manual process of collecting data. Work by Teizer et al. (2020) is a step towards automated WS, and the potential of further research in this area is clear. 
Implementing lean tools or other process optimization tools is by the authors seen as an essential initial step towards changing the construction industry. The authors do, though, believe that a more holistic and integrated approach is needed to solve the industry's problems. A well-proven holistic approach is integrated project delivery (IPD) (Fischer et al. 2017). IPD can be described as consisting of five elements (Neve et al. 2017) that consider the fundamental elements of a project with contract, culture, organization, Lean Construction, and building information modeling and recognizes that all elements are interdependent. This means that one cannot just solely focus on making the perfect contract and expect a successful project without also considering the remaining elements. IPD has proven itself to support innovation (Neve et al. 2017) and delivers projects on time and budget (Cheng et al. 2016), thus well-paved road forward.

\section{CONCLUSION}

Stagnation and decline in CLP have been documented in the USA, Canada, and EU. The development seen in CLP has considerable negative implications for the construction industry because labor cost constitutes up to $60 \%$ of the overall construction costs. Thus, knowledge is needed on how to change the current development in CLP.

It was found that the use of lean construction methods can increase CLE and, hereby, CLP in renovation projects. A strong positive correlation between the degree to which lean construction methods were implemented and CLE levels was documented by analyzing four renovation projects.

The results have implications for both academia and industry professionals. Academia now has initial results on which future research can be built. Industry professionals now have a better understanding and hereby argument for why lean construction methods must be implemented in future renovation projects.

The research was limited by a small sample size of four renovation projects. Thus, further research is needed to confirm further the effects in renovation projects but also other type of construction projects.

\section{REFERENCES}

Alarcón, L. F., Diethelm, S., Rojo, O., and Calderon, R. (2005). "Assessing the Impacts of Implementing Lean Construction." Proc. 13rd Ann. Conf. Int. Group for Lean Sydney, Australia.

AlSehaimi, A., Tzortzopoulos, P., and Koskela, L. (2009). "Last Planner System: Experiences From Pilot Implementation in the Middle East." Proc. 17th Ann. Conf. Int. Group for Lean Constr., Taipai, Taiwan.

Ballard, G. (2000). "The Last Planner System of Production Control." PhD Dissertation, School of Civil Engineering, University of Birmingham.

Buchan, R., Fleming, F. E., and Grant, F. E. K. (2006). Estimating for builders and quantity surveyors. MA, USA: Elsevier Butterworth-Heinemann.

Bølviken, T., Rooke, J., \& Koskela, L. "The Wastes in Construction - A TFV Based Taxonomy." Proc. 22nd Ann. Conf. Int. Group for Lean Constr., Oslo, Norway.

Caldas, C. H., Kim, J.-Y., Haas, C. T., Goodrum, P. M., and Zhang, D. (2015). "Method to Assess the Level of Implementation of Productivity Practices on Industrial Projects." J. Constr. Eng. Manage. 141 (1).

Cheng, R., Johnson, A. J., Allison, M., Monson, C., Staub-French, S., and Dossick, C. S. (2016). "MOTIVATION AND MEANS: How and Why IPD and Lean Lead to Success." IPDA: Integrated project Delivery Alliance \& LCI 
CII (2010). "Guide to activty analysis." Construction Industry Institute (CII)

Cohen, J. (1988). Statistical power analysis for the behavioral sciences. US: Lawrence Erlbaum Associates, Publishers.

Cohen, J. (1992). "A power primer." Psychological bulletin. 112 (1): 155-159.

Evinger, J., Mouflard, C., and Seppänen, O. (2013). "Productivity Effects of Starting as Early as Possible in Hospital Construction." Proc. 21 st Ann. Conf. Int. Group for Lean Constr., Fortaleza, Brazil.

Farmer, M. (2016). "The Farmer Review of The Uk Construction Labour Model." Construction Leadership Council.

Fischer, M., Khanzode, A., Reed, D., and Ashcraft, H. W. (2017). Integrating project delivery. USA: John Wiley \& Sons.

Gong, J., Borcherding, J. D., and Caldas, C. H. (2011). "Effectiveness of craft time utilization in construction projects." J. Constr. Manage. Econ. 29 (7): 737-751.

Gouett, M. C., Haas, C. T., Goodrum, P. M., and Caldas, C. H. (2011). "Activity Analysis for Direct-Work Rate Improvement in Construction." J. Constr. Eng. Manage. 137 (12): 1117-1124.

Heinonen, A., and Seppänen, O. "Takt Time Planning: Lessons for Construction Industry from a Cruise Ship Cabin Refurbishment Case Study." Proc. 24th Ann. Conf. Int. Group for Lean Constr., Boston, USA.

Hwang, B.-G., Krishnankutty, P., Zhu, L., Caldas, C. H., Shounak, A., and Mulva, S. (2018). "Improving Labour Productivity in Process Construction Maintenance and Shutdown/Turnaround Projects." Int. J. of Constr. Manage.: 1-15.

Kazaz, A., Manisali, E., \& Ulubeyli, S. (2008). "Effect of basic motivational factors on construction workforce productivity" J. of Civ. Eng. \& Mgmt. 14 (2): 95-106.

Kemmer, S. (2018). "Development of a Method for Construction Management in Refurbishment Projects." Diss., The University of Huddersfield, Huddersfield, UK.

Kenley, R., and Seppänen, O. (2010). Location-Based Management for Construction Planning, schedueling and control. UK: Spoon Press.

Koskela, L. (1992). "Application of the new production theory to construction."

Koskela, L. (2000). "An exploration towards a production theory and its application to construction." PhD, VTT Technical Research Centre of Finland.

Lerche, J., Neve, H., Pedersen, K. B., Wandahl, S., and Gross, A. (2019b). "Why Would Location-Based Scheduling Be Applicable for Offshore Oil and Gas Construction?" Proc. 27th Ann. Conf. Int. Group for Lean Constr., Dublin, Ireland.

Lerche, J., Neve, H., Wandah, S., and Gross, A. (2020b). "Continuous Improvements at Operator Level." Journal of Engineering, Project and Production Management. 10 (1): 64-70.

Lerche, J., Neve, H. H., Ballard, G., Teizer, J., Wandahl, S., and Gross, A. (2020a). "Application of Last Planner System to Modular Offshore Wind Construction." Journal of Construction Engineering and Management. 146 (11)

Lerche, J., Seppänen, O., Pedersen, K. B., Neve, H., Wandahl, S., and Gross, A. (2019a). "Why Would Location-Based Scheduling Be Applicable for Offshore Wind Turbine Construction?" Proc. 27th Ann. Conf. Int. Group for Lean Constr., Dublin, Ireland.

Lindhard, S. (2014). "Understanding the Effect of Variation in a Production System." J. Constr. Eng. Manage. 140 (11): 04014051.

Lindhard, S., and Wandahl, S. (2014). "Scheduling of large, complex, and constrained construction projects - an exploration of LPS application." International Journal of Project Organisation and Management. 6 (3): 237-253. 
Nasir, H., Haas, C. T., Caldas, C. H., and Goodrum, P. M. (2016). "An Integrated Productivity-Practices Implementation Index for Planning the Execution of Infrastructure Projects." J. of Infrastructure Systems. 22 (2)

Neve, H., and Wandahl, S. (2018). "Towards identifying Making-Do as lead Waste in Refurbishment projects." Proc. 26th Ann. Conf. Int. Group for Lean Constr., Chennai, India.

Neve, H., Wandahl, S., and Lerche, J. (2020d). "Feedback Loop: The missing link in activity analysis." In Proc., 10th EPPM conference.

Neve, H., Wandahl, S., Lindhard, S., Teizer, J., and Lerche, J. (2020a). "Determining the relationship between direct work and construction labor productivity in North America: Four decades of insights." J. Constr. Eng. Manage. 146 (9)

Neve, H., Wandahl, S., lindhard, S., Teizer, J., and Lerche, J. (2020b). "Learning to see value-adding and nonvalue-adding work time in refurbishment production systems." In Journal of Construction Engineering and Management, 146(9).

Neve, H. H., Wandahl, S., Kaeseler, S. M., and Tandrup, A. (2017). "INTEGRATING IPD AND EXPLORING POTENTIALS." In Proc., 33rd ARCOM.

Seppänen, O. (2014)."A Comparison of Takt Time and LBMS Planning Methods." Proc. 22nd Ann. Conf. Int. Group for Lean Constr., Oslo, Norway.

Seppänen, O., Ballard, G., and Pesonen, S. (2010). "The combination of last planner system and locationbased management system." LCJ. 6 (1): 43-54.

Seppänen, O., Evinger, J., and Mouflard, C. (2014). "Effects of the location-based management system on production rates and productivity." Construction Management and Economics. 32 (6)

Smith, R. (2013). Estimating and tendering for Building work. NY, USA: Routledge.

Teizer, J., Neve, H., Li, H., Wandahl, S., Koenig, J., Ochner, B., König, M., and Lerche, J. (2020). "Construction Resource Efficiency Improvement by Long Range Wide Area Network Tracking and Monitoring." Automation in Construction.

Thompson, S. K. (1987). "Sample size for estimating multinomial proportions." The American Statistician. 41 (1): 42-46.

Thompson, S. K. (1992). Sampling. Hoboken, New Jersey, USA: Wiley.

Tommelein, I. D., Riley, D. R., and Howell, G. A. (1999). "Parade Game: Impact of Work Flow Variability on Trade Performance." J. Constr. Eng. Manage. 125 (5): 304-310.

Wandahl, S. (2014). "Lean Construction with or without Lean - Challenges of Implementing Lean Construction." Proc. 22nd Ann. Conf. Int. Group for Lean Constr., Oslo, Norway. 